\title{
Reflexiones sobre Trabajo Social: aportes de la Sistematización
}

\section{Reflections on Social Work: contributions of Systematization}

\author{
María Rocío Cifuentes-Patiño \\ Doctora en Humanidades. Trabajadora Social \\ Universidad de Caldas. Manizales, Colombia \\ https://orcid.org/0000-0002-3899-0017• maria.cifuentes@ucaldas.edu.co
}

\begin{abstract}
Opté a conciencia por contar lo que me habían contado, diría mejor, lo que me habían confiado. Lo escribí en primera persona como si ellos, los colonos, lo hubieran escrito. Tal subjetividad dictaminó la doctrina- reñía con la naturaleza objetiva y aséptica de la ciencia. No se podía distinguir entre la verdad y la fantasía. Para mí, la cuestión no era de método sino de ética. Se produjo entonces un rompimiento a ciencia y conciencia, una "ruptura epistemológica" con lo que parecía más un juez que un maestro. (Molano-Bravo, 2020, p. 300) ${ }^{1}$
\end{abstract}

En tiempo de balance -hablo del tiempo personal- las coincidencias llegan, para recordar que siempre venimos siendo y que las experiencias y las apuestas, académicas, éticas y políticas, están incorporadas en el proceso nunca concluido de estudiar, aprender, actuar y formarse. Esta alusión tan propia, en cuanto mía, pero, quizás impropia en un texto académico, que quienes leen me sabrán disculpar, es para expresar gratitud por invitarme a escribir la página editorial de Prospectiva, Revista de Trabajo Social e Intervención Social, $\mathrm{N}^{\mathrm{o}} 31$.

Este número de la revista pone en conversación textos de varias de las personas reconocidas por sus aportes al desarrollo de la Sistematización en el país y en el continente, trabajadoras sociales y educadores populares, principalmente. La editora invitada es la colega, amiga y compañera de muchas lides, Rosa María Cifuentes Gil quien, por años, viene

1 El subrayado es mío.

Recibido: 21/11/2020 | Aprobado: 15/12/2020 |Publicado: 01/01/2021

cc)(7) Esta obra está bajo una Licencia Creative Commons Atribución-NoComercialCompartirIgual 4.0 Internacional.

\section{¿Cómo citar este artículo? / How to quote this article?}

Cifuentes-Patiño, M. R. (2021). Reflexiones sobre Trabajo Social: aportes de la Sistematización. Prospectiva. Revista de Trabajo Social e intervención social, (31), 11-26. doi: 10.25100/prts.v0i31.10887. 
Cifuentes-Patiño

produciendo en torno a la sistematización y la formación en esta, para Trabajo Social. En coherencia con el sentido de la sistematización, incluye esta edición artículos resultado de la reconstrucción de experiencias de acción educativa y social. No me ocuparé de referenciar a las y los autores que escriben en esta edición, como reconocimiento a sus aportes al tema, ni a los artículos.

Las ideas que presento son fruto de lecturas y conversaciones que he sostenido con múltiples textos, algunos de autoría de los invitados a esta edición. También están influenciadas por las conversaciones con estudiantes y actores de las prácticas sociales en los procesos de reconstrucción de éstas.

Ubicándome en el nombre de la Revista y en el asunto central del cual se ocupa esta edición, opté por escribir un texto desde debates actuales sobre el Trabajo Social y el lugar de la relación intervención-investigación en ellos, que resulta nuclear para abordar el rol que podría jugar la sistematización en el proceso siempre inacabado de construcción profesional y, en consecuencia, en los procesos de formación en Trabajo Social.

Como preámbulo, haré una breve referencia a tres controversias actuales en Trabajo Social: 1) La comprensión de su historia. 2) Sus fines. 3) Su estatuto profesional o disciplinar. En este marco me referiré a algunos rasgos que caracterizan a la sistematización como un tipo de investigación propia del Trabajo Social. Cuando digo propia no hablo de "pertenencia exclusiva", me refiero a otras acepciones definidas en la RAE: "conveniente, adecuada" y "principal o fundamental". También me refiero, por supuesto, a los aportes tanto del Trabajo Social como de la Educación Popular, para la creación de este tipo de investigación, desarrollada en América Latina, en búsqueda de pertinencia contextual, ética y política.

\section{1. ¿Cómo leemos la historia del Trabajo Social?}

Dudo que haya otra profesión que se cuestione tanto a sí misma y que presente en forma tan descalificadora el pasado profesional [...] El desconocimiento de las potencialidades y logros de la práctica del trabajo social condujo a ver sólo sus carencias y limitaciones. (Aylwin, 1999, p. 14)

El surgimiento del Trabajo Social se enraíza en el complejo y disputado campo de las Ciencias Sociales, hijas de la modernidad y ligadas a los intereses del modelo económico capitalista. En este campo ha ocupado un lugar subalterno al cual se ha adaptado o se ha resistido, dando origen a diversas comprensiones del Trabajo Social.

Fieles a nuestra tradición de autocrítica, a la reflexividad y a la diversidad que nos han caracterizado, las lecturas sobre el surgimiento y el devenir del Trabajo Social, hoy después de casi un siglo de existencia en el Continente, han sido interrogadas y constituyen un 
Cifuentes-Patiño

campo de tensiones. De ello se deriva que asuntos cruciales de orden epistemológico, teórico, ontológico, metodológico y, por supuesto, ético-político, sean fuente de debate. Coexisten diferentes tesis explicativas del desarrollo histórico del Trabajo Social. Afirman Leal y Malagón (2006) que en esas comprensiones hay incongruencias que es necesario superar.

La primera consiste en leer la historia de la profesión en el surgimiento de un dispositivo de ayuda, inspirado en la caridad de corte cristiano católico y centrado en la atención de los pobres, llamado asistencia social [...]

La segunda incongruencia tiene que ver con un encuadre profundamente sesgado que desestimó los desarrollos alcanzados por el trabajo social antes de 1970, al considerarlos, bajo la influencia del ideario católico, como "asistencialistas", funcionalistas y comprometidos con la perpetuación del establecimiento. [...]

Una tercera incongruencia, resultado directo de la anterior, consiste en la construcción de periodizaciones mesiánicas, en las cuales el pensamiento elaborado entre los años setenta y los noventa se muestra como el completo y verdadero trabajo social. (p. 47).

En los 14 años pasados desde esa publicación, el debate ha continuado: nuevos autores han entrado en él, se han desarrollado posturas con otros elementos teóricos e históricos, como la investigación generada en torno a las pioneras del Trabajo Social por el Grupo Interuniversitario de Investigadores en Trabajo Social (GIITS), las aproximaciones de carácter decolonial y la emergencia de la categoría de género como clave para entender este devenir.

En un texto del Consejo Nacional para la Educación en Trabajo Social (CONETS, 2020), que será objeto de discusión en las escuelas el próximo año, se establece que "La trayectoria de Trabajo Social debe leerse en relación con las Ciencias Sociales involucrando, también, formas de configuración por fuera de sus cánones" (p. 15)². Articulo esta aseveración al tema de sistematización, pues esa forma de investigación, no considerada en los estrechos márgenes de "La Ciencia", es parte de desarrollos en cuya construcción ha participado Trabajo Social, en autonomía y contestación a los límites canónicos a la producción de "conocimiento científico".

En el documento del CONETS se condensaron lecturas de los orígenes y desarrollo del Trabajo Social, en tres tendencias preponderantes, a saber:

1) La evolucionista, relacionada con el paso de las acciones de caridad y filantropía, a la profesión (Lima, 1976; Ander-Egg, 1994). 2) La histórico-crítica, centrada en la génesis en el marco del sistema capitalista monopolista (Montaño, 2000). 3) La académico- pragmatista, basada en el reconocimiento de espacios académicos, de acción y de movilización profesional y política de las fundadoras (Travi, 2006; Miranda, 2010). (CONETS, 2020).

2 El subrayado es mío 
Cifuentes-Patiño

La diversidad de lecturas contemporáneas de la trayectoria histórica, no se agota en estas tendencias; cada una es heterogénea y hay lugar a hibridaciones entre ellas.

Esta mínima alusión al tema de la historia, tiene en este texto el propósito de señalar que la producción de conocimientos y, en relación con ello, la investigación, han sido categorías involucradas en la comprensión de la historia del Trabajo Social. En unos casos, se aduce que la producción de "conocimiento científico propio", es ajena a las lógicas de las profesiones, consideradas como consumidoras de saberes producidos por las disciplinas. En otros se desarrollan posturas críticas frente a los postulados orientados a precisar la especificidad, a delimitar métodos y a establecer un objeto "propio" de conocimiento. En otros se investiga y reconoce la producción de conocimiento desde sus orígenes y a lo largo de la trayectoria del Trabajo Social.

En otros más, porque se aboga por la necesidad no sólo de un conocimiento disciplinar, sino también pertinente para las realidades sociales latinoamericanas, en oposición a la colonización epistémica de la que hemos sido objeto. Y, por último -el lugar es aleatorio- se considera que es nota distintiva del Trabajo Social la producción de conocimientos acerca de las realidades sociales de las que se ocupa ${ }^{3}$ y del propio quehacer, como un ejercicio de reflexividad ${ }^{4}$, de valoración de los saberes producidos en la acción y de asumir la transdisciplinariedad ${ }^{5}$ como uno de los principios orientadores de la intervención y de la investigación social. Este es un lugar nuclear para entender el papel de la sistematización en Trabajo Social, como aporte a su propio desarrollo, a la academia y a la ecología de saberes ${ }^{6}$.

\section{Los fines del Trabajo Social}

El debate sobre los fines del Trabajo Social ha estado ligado a la discusión en relación a cómo se entiende y a las lógicas que han signado su constitución histórica. Para no excederme en la extensión del texto, aunque es un tema de cardinal importancia, me limito a enfatizar dos asuntos: el que critico, y el que asumo. Uno y otro, suelen darse por obvios y sobreentendidos, lo que implica el riesgo de que resulten ignorados.

3 Entendidas estas como problemas, conflictos, necesidades, procesos, injusticias sociales o cuestión social, entre otras, dependiendo de la noción que se tenga del objeto.

4 Capacidad de volver sobre sí críticamente e interpelarse en búsqueda de compromiso ético.

5 Supera la lógica del trabajo entre disciplinas, para plantearse más allá de este y, además, valorar otros actores sociales como sujetos productores de conocimiento. Desde este punto de vista el conocimiento se construye en relación dialógica y no está circunscrito al mundo de la academia.

6 "La ecología de saberes como justicia cognitiva orientada a reconocer pluralidad de sujetos indispensables en la construcción de procesos participativos" (Cifuentes-Patiño, 2019, p. 109). 
Cifuentes-Patiño

A Trabajo Social se le ha señalado -interna y externamente- de perseguir fines de adaptación, funcionales al ordenamiento capitalista y a su reproducción. Sin embargo, desde sus orígenes y a lo largo de su historia, se ha registrado compromiso del lado de quienes son sometidos a opresiones sociales diversas y son víctimas de la desigualdad en la que asienta sus bases la jerarquizada e injusta sociedad capitalista, patriarcal y colonial. Las luchas políticas de las pioneras, los postulados de la reconceptualización y las diversas vertientes del Trabajo Social Crítico contemporáneo, son ejemplos de ello. Estas tendencias han discurrido en tensión con formas de entender el Trabajo Social como profesión centrada en un quehacer de carácter pragmático-instrumental. Este corresponde a intereses institucionales, en el marco de políticas abiertamente regresivas o, evocando a Fraser (2015), en algunos casos afirmativas, sin dar lugar a reivindicaciones de carácter transformativo. Se trata de una perspectiva profesional centrada en el quehacer que responde a objetivos inmediatistas, en los que no cabe la pregunta por la transformación social, por tanto, sin aspiraciones de producción de conocimiento. Dice Ghiso (2011) sin mencionar directamente al Trabajo Social, pero, aplicable a este:

No es raro, hoy, ver a profesionales de las ciencias sociales [...] enfrentados a la tarea desgastante de diligenciar planillas, esquemas y listados, enumerando actividades, participantes y recursos utilizados; señalando con una " $x$ " el grado de éxito y el porcentaje de logro alcanzado; generando información mediante modelos e instrumentos que los inhabilitan y aquietan en su capacidad reflexiva.

No es tampoco ajeno a la realidad reconocer que una cosa es la que se pone en los papeles y otra diferente la que sucede [...] transmitiendo de esa manera informaciones que encubren los fenómenos y conflictos sociales, nutriendo el diseño de políticas que se aplican, ejecutan e imponen sobre comunidades y profesionales, fortaleciendo un sistema donde el silenciamiento, el empequeñecimiento y la sistemática exclusión marcan la cotidianidad y el futuro de la gente. (pp. 3-4)

Desde el compromiso con quienes son víctimas de formas diversas de opresión ${ }^{7}$ (de clase, género, generación, etnia, identidad sexual, condiciones de salud física y mental... entre otros) en América Latina se postulan voces que abogan por un Trabajo Social comprometido con la emancipación social. Es decir, encauzado a desenmascarar las opresiones, los sistemas en que estas se asientan (capitalismo, patriarcado, colonialidad) y los impactos en sujetos, en colectivos y en el planeta. Es un Trabajo Social cuyo quehacer no se agota en la intervención, que sitúa en lugar de cardinal importancia a la investigación y asume que, más allá de los marcos formales de la academia, el conocimiento social también se produce en la acción social. En esta comprensión se reconocen los actores sociales como productores de saber, sujetos políticos que, a través de la participación, construyen, con otros, saberes válidos e indispensables para reconocer y transformar sus propias realidades.

7 Propone Young (2000) que son cinco las caras de la opresión: explotación, marginación, carencia de poder, imperialismo cultural, violencia estructural. Estas se presentan imbricadas en la vida social e involucran opresiones tanto de clase, como culturales y políticas.

Prospectiva. Revista de Trabajo Social e intervención social • No. $31 \bullet$ ene.-jun. $2021 \bullet$ pp. 11-26 e-ISSN: 2389-993X • https://doi.org/10.25100/prts.v0i31.10887 
Cifuentes-Patiño

Se configura así el nicho que contribuyó a la concepción y el desarrollo de la sistematización como forma de producción de conocimientos sobre la acción. Esta perspectiva está compuesta por un grupo heterogéneo de tendencias críticas que suelen reconocerse más en sus diferencias que en sus afinidades, ellas comparten el entendimiento de que una nota distintiva del Trabajo Social es su compromiso con la transformación en horizontes de emancipación social. De ello se derivan fines específicos diversos, en coherencia con las opresiones priorizadas y las fuentes epistemológicas y teóricas que nutren las lecturas de ellas.

\section{El debate profesión-disciplina}

Derivado de lo referido, se registra hoy un debate en torno al estatuto disciplinar del Trabajo Social, que no siempre trasciende de los espacios académicos a los gremiales y al ejercicio profesional.

En el documento del CONETS (2020) se identifican orientaciones diversas que, a riesgo de simplificar un panorama complejo y heterogéneo, podrían sintetizarse en tres tendencias: el Trabajo social como profesión, como disciplina o como indisciplina de las Ciencias Sociales. Ninguna es unívoca; en cada una coexisten miradas sobre el nexo intervención-investigación social, su objeto, las aproximaciones epistemológicas y los debates metodológicos, todo lo cual relaciono con el lugar de la sistematización de experiencias en el Trabajo Social. Sin pretensiones de exhaustividad y con la mirada en la díada intervención-investigación, me acerco a estas perspectivas.

En la tendencia que asume el Trabajo Social como profesión hay diversas lecturas. Una crítica de raigambre marxista que enfoca el lugar de la profesión en la división socio-técnica del Trabajo; se postula que la profesión nació y ha construido su historia al tenor del surgimiento y desarrollo del sistema capitalista, en el que le ha correspondido atender las manifestaciones de la cuestión social y la mediación que el Estado hace de ellas. Tal ubicación marca contradicciones entre sus fines y su desempeño en la política social y la institucionalidad encargada de realizarla. Molina (2010) plantea que "todo nuestro trabajo profesional se reproduce en la tensión entre: los intereses hegemónicos consecuentes con un modo de vida y la aspiración ética de otro mundo posible con justicia social y libertad" (p. 2).

De otra parte, hay quienes reivindican el lugar del Trabajo Social como profesión de la acción, productora de conocimiento, comprometida con el cambio social en lógicas de igualdad y equidad. En esta aproximación se plantea que la investigación en Trabajo Social, no puede circunscribirse a formas canónicas de producir conocimientos en las que se privilegia el saber académico, postulados de objetividad, cientificidad, separación jerárquica entre sujetos productores de conocimiento y aquellos sobre los que se produce (sujetos y 
Cifuentes-Patiño

objetos de investigación) y se disocia la producción del conocimiento y su uso social. Sobre estos postulados se ha asentado la diferenciación jerárquica entre las disciplinas como productoras y las profesiones como consumidoras de conocimiento, que para Trabajo Social implicó la atribución histórica de la intervención y la supuesta distancia con la investigación. La academia es un campo atravesado por relaciones de poder que instituye barreras a las profesiones relacionales, a las que han confinado a las orillas de la intervención. MosqueraRosero-Labbé (2013) revela que "Esta frontera las relegó al rango de simples ejecutoras sin la posibilidad real ni simbólica de ser protagonistas de "la democratización, legitimación y pluralización epistémica de la ciencia" (p. 263). Así, frente a la intervención como práctica social y a los actores participantes en la misma, se erigió una barrera cognitiva. De Sousa (2005) postula el concepto "epistemicidio de saberes" que pareciera pertinente para esta situación.

En resistencia a esa ubicación subalterna y excluyente, la perspectiva que reivindica el lugar del Trabajo Social como profesión de la acción, productora de conocimientos válidos e indispensables para la transformación social, aboga por valorar la intervención como productora de saber y por una necesaria democratización de la ciencia. En referencia a las universidades públicas, extrapolable a este entendimiento del Trabajo Social, propone De Sousa (2005) la ecología de saberes “[...] conjunto de prácticas que promueven una nueva convivencia activa de saberes [...] todos ellos, incluido el saber científico, se pueden enriquecer en este diálogo" (p. 33). La sistematización como tipo de investigación cuyo objeto de conocimiento es la práctica social, puede ser aliada de esta perspectiva que valora los saberes producidos en la acción y se compromete con la emancipación social.

También se asume el Trabajo Social como profesión desde otras lógicas que lo entienden como campo privilegiado de acción y de intervención en el marco de las políticas públicas y de la institucionalidad. Así, se enfatiza en el acervo metodológico construido en la historia y al tenor de saberes disciplinares, en respuesta a las demandas que la problemática social plantea a las profesiones sociales. Se centra la especificidad y la fortaleza profesional en aspectos metodológicos y técnico-operativos del quehacer, en respuesta a objetivos relacionados con la prestación de servicios, definidos por lineamientos y parámetros institucionales.

La segunda tendencia ubica al Trabajo Social como disciplina social. El debate sobre el estatuto disciplinar ha tomado fuerza en el Trabajo Social latinoamericano. De este participan quienes lo dan por establecido y reclaman el reconocimiento de campos propios de acción, conocimientos específicos y desarrollos metodológicos; también quienes lo postulan como propósito en construcción que implica desarrollos sistemáticos en la producción de conocimientos y quienes reconocen la doble calidad de profesión-disciplina. En los intersticios de este proceso de transformación se ubican, entre otros, aportes de la perspectiva decolonial del Trabajo Social. En el centro de la discusión disciplinar, están la 
Cifuentes-Patiño

investigación y la producción de conocimientos como rasgos constitutivos del Trabajo Social, asociados a fines de transformación en los que tienen cabida discusión y desarrollos sobre la sistematización. Asuntos como la intervención y su objeto, entran de maneras diversas en esta controversia.

Finalmente, se viene postulando una mirada de resistencia a lógicas convencionales de la ciencia y a la dicotomía entre profesiones y disciplinas; se reconoce el carácter indisciplinado del Trabajo Social a lo largo de su historia. Con ello se refiere a diferencias en la constitución del Trabajo Social, tales como: el género de las pioneras y de la mayoría de quienes aún componemos el colectivo profesional, el énfasis en los fines y en su indisoluble relación con la ética y la política, el respeto a la pluralidad interna y en la relación con los actores sociales (que desafía lógicas como la supuesta "objetividad de la Ciencia Social", la preeminencia y la distancia del "investigador" de aquello que investiga) y el reconocimiento de la transdisciplinariedad como principio de investigación e intervención. Las reflexiones que se construyen desde el Trabajo Social beben y les aportan a las surgidas en otras orillas de las Ciencias Sociales. La actual presidenta de la Federación internacional de Trabajo Social planteó en un evento reciente organizado por la Universidad de Caldas:

Ante esta realidad cambiante, multifacética, contradictoria, imprevisible profundamente injusta y desigual, signada por una racionalidad neoliberal, necesitamos problematizar no sólo la formación de los/as Trabajadores/as Sociales, sino la realidad misma. Problematizar no quiere decir constituir a la realidad como problema sino, ante todo, transformar la realidad en ámbito problemático (Zemelman, 1987), es decir, transformar lo dado en potencia a partir de una epistemología indisciplinada que habilite la capacidad crítica de pensar, es decir que habilita la tarea política de pensar el pensar. (Martínez, 2020)

Extrapolo estos argumentos para decir que la Sistematización es un tipo de investigación fundado en una epistemología claramente indisciplinada, que aporta a las búsquedas de Trabajo Social, en tanto permite ejercitar la reflexividad, decantar los conocimientos producidos en la acción, articular intervención-investigación, desarrollar la pluralidad, reconocer las diferencias y la capacidad de construir conocimiento y transformación desde ellas. Es un conocimiento que permite tender puentes entre formas tradicionales e indisciplinadas de investigación, paradójicamente, estas últimas se refieren a un quehacer disciplinado, riguroso en sus demandas de coherencia interna y externa y pertinencia con los fines éticos y políticos de transformación social. 
Cifuentes-Patiño

\section{La sistematización, puente entre la intervención y la investigación}

En el trípode intervención-investigación-fines, la Sistematización como posibilidad de reconstruir, circular y debatir, los saberes producidos en la acción, con actores sociales diversos, se erige como puente que permite conectar intervención e investigación, anudadas a los propósitos de reconocimiento, inclusión y justicia, del Trabajo Social. (Cifuentes-Patiño, 2015, p.

4)

En este recorrido por tres asuntos involucrados en discusiones vigentes del Trabajo Social, que no son los únicos temas de debate, he intentado evidenciar que el actual Trabajo Social es diverso $\mathrm{y}$, por tanto, la pluralidad ha de ser un principio subyacente a su construcción, siempre inacabada. De lo anterior dan cuenta, temas de carácter ontológico, epistemológico y ético-político que he traído a colación (historia, fines, debate profesióndisciplina), también otras categorías claves desde las que se interpela hoy la profesión. Aunque me he centrado en estos tres temas, considero que los debates actuales se enriquecen con perspectivas que involucran categorías tan potentes como género, decolonialidad, interseccionalidad ${ }^{8}$, cuidado y ecología política ${ }^{9}$, entre otras.

El retorno a esos tres temas, que algunos puedan considerar como una anacrónica reedición de debates añejos, es clave, por lo menos, en dos sentidos. De una parte, porque siguen siendo asuntos abiertos y en discusión enriquecedora, nutrida por nuevas categorías de análisis y desde diversas lógicas teóricas. De otra parte, porque en ellos se involucran, como asuntos nucleares, la investigación y la producción de conocimientos. Es en este último sentido, en el que me propuse establecer una relación directa con el tema de la sistematización, la que he venido pespunteando a lo largo del Texto.

La investigación ha estado presente en Trabajo Social desde sus inicios, aunque, por supuesto, ocupando lugares distintos y con énfasis diversos, relacionados con:

- $\quad$ El diálogo no siempre fluido con la cuestión social, la política y las instituciones sociales.

- Las también complejas relaciones con las Ciencias Humanas y Sociales y las perspectivas epistemológicas y teóricas derivadas de ellas.

8 La interseccionalidad es "la expresión utilizada para designar la perspectiva teórica y metodológica que busca dar cuenta de la percepción cruzada o imbricada de las relaciones de poder" (Viveros, 2016, p. 1)

9 [...] elemento esencial de la mutación cultural que vivimos, porque aporta la conciencia de los límites de la acción humana organizada y técnica [...] el ser humano ya no es el conquistador de una naturaleza en la que abría con grandes esfuerzos un claro: al haber alcanzado los medios de transformar y hasta destruir su planeta, se ha vuelto responsable de él. Su acción ya no puede estar animada por la confianza de un progreso sin fin; debe estarlo por la conciencia de las amenazas que pesan sobre la supervivencia de la humanidad, y en particular la necesidad de salvaguardar la diversidad de las especies y las culturas (Touraine, 2000, p. 305). 
- $\quad$ Los enfoques del Trabajo Social en uso y en debate.

- Los desarrollos de la práctica, campo rico en controversias, dilemas, hipótesis e interpelaciones por la pertinencia histórica y por la coherencia entre quehacer y discursos constitutivos.

A pesar de la relación permanente con la investigación, al Trabajo Social, denotado como profesión de la acción (hay distancias entre acción instrumental y acción fundamentada), se le ha intentado reducir a la intervención, que supuestamente depende de saberes de las disciplinas sociales, para orientar la comprensión de aquello en lo que se interviene (marco teórico), o derivar las formas de intervención (metodologías). La intervención se ha usado como pretexto para anclar el Trabajo Social a una posición subalterna, que ha resistido de maneras diversas. No obstante, la subvalorada intervención, ha sido y es fuente de producción de saberes, nodo de conexión con la investigación y con los fines ético-políticos de transformación social. En las cada vez más porosas relaciones entre disciplinas y profesiones, aquellas se han ido acercando al campo de la intervención en respuesta a las demandas del campo laboral y a los reclamos éticos con respecto a los usos sociales del conocimiento. Plantea Mosquera-Rosero-Labbé (2013):

[...] en la actualidad [...] personas de otras áreas del conocimiento científico, antropólogos y sociólogos especialmente, han incursionado en el espacio de la acción social, y problematizan no sólo la hegemonía que tenían las profesiones relacionales [...] sobre los escenarios de intervención [...] plantean la pregunta de qué hacen o qué harán en este espacio los que otrora eran vistos como [...] los llamados a pensar y a crear el conocimiento científico, para que las ciencias sociales aplicadas o las profesiones relacionales se encargaran de la utilidad del mismo. (p. 54)

La vilipendiada intervención emerge como fortaleza del Trabajo Social, pues involucra acción e investigación, en procesos de transformación social. En ella, entendida desde perspectivas críticas, se acopian conocimientos, propios y de otras disciplinas, y se producen nuevos saberes que revitalizan los procesos y dignifican el lugar de los actores sociales como sujetos epistémicos y políticos. No toda intervención se inscribe en esta perspectiva: la coherencia con los fines y los principios del Trabajo Social es el tamiz que lo define. Desde lógicas críticas, en plural, porque así sucede en el actual ámbito profesional, los fines se refieren al compromiso con la transformación social, en horizontes de emancipación y justicia social. Estamos en mora de cuestionarnos respecto a los principios, no tanto para consensuar y priorizar un listado, sino para reconocerlos como eje que estructura, sostiene y orienta la profesión. Estos tienen aristas éticas y políticas. Para la formación en Trabajo Social, propone la actual presidenta de la FITS involucrar, entre otros: pluriversidad, transdisciplinariedad, interdisciplinariedad e interseccionalidad (Martínez, 2020). Considero que la participación debe tener un lugar central entre ellos, aunque también en los fines y en los medios. Asuntos como reflexividad, reconocimiento, intersubjetividad, 
Cifuentes-Patiño

coherencia, pertinencia y contextualización, entre otros, deben entrar en el debate al respecto.

La sistematización se gestó por vía de la práctica social y de las búsquedas en ella instauradas, en épocas en que soplaban vientos de cambio, en resistencia a modelos económicos, políticos y académicos, impuestos en América Latina desde otras latitudes. Esta nació como como apuesta propia de investigación, que se planteó críticamente frente los cánones sobre los que se erigió la Ciencia Moderna y asumió el desafío de constituir las propias prácticas en fuente de producción de saber y de cambio social.

Entiendo la Sistematización, como afirmé de entrada, como un tipo de investigación social. Su objeto de conocimiento que, a mí modo de ver, permite diferenciarla de cualquier otro tipo de investigación, son las experiencias sociales; otros las entienden como prácticas sociales o procesos sociales. Los rasgos que la constituyen en lo que atrás referí como un tipo de investigación, epistemológica y metodológicamente indisciplinado, son, entre otros:

1. Es una investigación cualitativa de caso, situada contextualmente, por lo tanto, sin pretensiones de generalización, lo que marca una de las muchas diferencias con las investigaciones de corte empírico-analítico.

2. A pesar de lo anterior, en esta investigación no se entiende el caso de manera aislada; su lógica contextual implica asumir que los procesos sociales están indisolublemente relacionados con las condiciones históricas, políticas, culturales y, en fin, territoriales en que se realizan. Así, además de identificar, comprender y relacionar las categorías idiosincráticas de la experiencia, con la sistematización se busca entenderla, en el marco de las relaciones estructurales que la signan, le imponen límites o le abren posibilidades.

3. Las perspectivas epistemológicas de corte histórico-hermenéutico y discursivo nutren la sistematización, en coherencia con el interés de comprender los procesos tejidos colectivamente, los sentidos que los participantes les atribuyen y la construcción dialógica de saberes.

4. La perspectiva crítico social es clave en este tipo de investigación. Con la Sistematización se busca reconstruir y comprender las experiencias con las y los actores de ellas, asumidos como sujetos epistémicos portadores de saberes y en capacidad de construir, con otras y otros, conocimientos acerca de sus propias prácticas sociales. En lógicas de democratización del saber, las y los actores asumen el rol de co-investigadores de los procesos desarrollados en pos de un cambio social y reconocen, apropian y proyectan los saberes, conjuntamente generados. De esta manera, la transdisciplinariedad emerge como uno de sus 
Cifuentes-Patiño

principios. Es propósito de la Sistematización poner el conocimiento producido al servicio de la propia experiencia y de otras afines, como posibilidad de producir sinergias en torno a los fines de cambio social y resistencias frente a las opresiones, que constituyen obstáculos para procesos de emancipación social.

5. Se trata de una investigación que parte de la práctica social y retorna a ella para fortalecerla. Afirmó Molano-Bravo (2020), “El conocimiento es una especie de hijo pródigo que sólo encuentra suspiro cuando regresa a su fuente" (p. 302). La práctica se constituye en objeto de conocimiento y los actores de ella en productores de esta, lo que desafía las pretensiones de objetividad de la ciencia. Así, la participación, concepto que también aquí corre el riesgo de parecer obsoleto o de convertirse en lugar común, se erige como fin, principio y estrategia nuclear para la sistematización. Los conocimientos y productos que la sistematización tributa a la práctica, se construyen en su seno y se ponen a su servicio y al de prácticas afines, principalmente, en el horizonte de cambio social. Así, la sistematización es una investigación que demanda un particular compromiso con el ciclo del conocimiento: a) Reconocimiento de las prácticas como portadoras de saber. b) Reconstrucción participativa de la experiencia. c) Comprensión compleja de la experiencia. d) Decantación de los saberes producidos en ella. e) Socialización de resultados. f) Apropiación y diseminación de saberes y retorno a la práctica con una comprensión enriquecida de la misma. Esta fase, que es finalización y reinicio, puede abrir compuertas para tejer convergencias a las que las lógicas de interseccionalidad resultan útiles.

6. La Sistematización involucra una relación medular con la dimensión temporal de los procesos. Tomo prestado de Ricoeur (2001) el concepto de éxtasis del tiempo, para referirme a la articulación que la sistematización permite entre el pasado, el presente y el futuro de las prácticas. Desde el presente, se interpela el pasado de la experiencia y se visita este reflexivamente para revivirlo, interpelarlo, reconocerlo, sorprenderse con él y comprenderlo. Se trata de un ejercicio de memoria, que demanda extrañamiento de la experiencia, cuestionamiento y reconstrucción de ella. Con base en tal proceso se traen al presente significados, huellas, saberes, dudas y nuevas preguntas e hipótesis, de acción y de conocimiento. Así, se busca develar las enseñanzas que entraña la experiencia, reconocer sus límites y sus posibilidades. Se cierra con la apertura al futuro, al que se proyecta lo aprendido. Todo el proceso podríamos sintetizarlo en: volver sobre el camino recorrido, caminar con la experiencia y aviar para continuar el camino. 
Cifuentes-Patiño

7. Para un proceso como el referido, en términos deliberadamente extraños a las formas convencionales de investigación, es evidente que no hay un modelo metodológico a aplicar. Es necesario el ejercicio de creación colectiva, que parte de formarse en la sistematización, acordar los fines, y apropiar los principios de este tipo de investigación. Con base en ello, se crea una bitácora coherente con los fines y principios establecidos, pertinente para la experiencia a reconstruir, factible para las condiciones de diferente índole en que se llevará a cabo, confiable en relación con los conocimientos que se reconstruyen y flexible en relación con las situaciones que interpelen su desarrollo. Se trata de idear una manera de reconstruir y escudriñar la experiencia buscando respuestas a las preguntas formuladas. Tiene como propósito descubrir en la experiencia lo que aún no se sabía de ella o que se ignoraba que se sabía; interpelarla y dejarla que sea maestra. El proceso proyectado está sujeto siempre al juicio reflexivo y a la deliberación de quienes lo están desarrollando. El diálogo es clave, porque, como diría Gadamer (2005), en el diálogo logrado se produce la fusión de horizontes de sentido de los participantes, es decir, aparecen nuevas formas de comprensión y se develan nuevas relaciones de sentido, que le imprimen a la comprensión una dinámica de movimiento y expansión.

[...] el modelo del diálogo puede aclarar la estructura de esta forma de participación. Porque el diálogo se caracteriza también por el hecho de no ser el individuo aislado el que conoce y afirma, el que domina una realidad, sino que esto se produce por la participación común en la verdad (Gadamer, 2004, p. 313).

8. La Sistematización se relaciona y se diferencia de otros tipos de investigación, por ejemplo, la diagnóstica, la evaluativa y la IAP. Aunque ellas se ocupen de las prácticas sociales, es en la sistematización que se constituyen en su objeto de conocimiento, con fines de comprensión y de transformación; las otras, pueden aportarle, pero, no sustituirla ni confundirse con esta. IAP, Educación Popular y Sistematización tienen estrechas afinidades: comparten el horizonte emancipador, interpelan las lógicas tradicionales de la "ciencia" y reconocen a sujetos y a los colectivos como actores válidos e indispensables de los procesos sociales: portadores de saber, productores de conocimiento y sujetos éticos y políticos. En razón de tales similitudes, son una tríada potente, que, en los procesos sociales, puede retroalimentarse $y$ fortalecerse mutuamente, para potenciar su poder transformador.

Después de este recorrido por algunos debates contemporáneos del Trabajo Social y por los que considero rasgos distintivos de la Sistematización, parece evidente que, por la cercanía en fines y por la nuclear relación entre práctica social e investigación, la formación en sistematización se constituye en una posibilidad para el logro de objetivos curriculares y para el fortalecimiento del Trabajo Social. Al respecto hay avances en diferentes escuelas de 
Cifuentes-Patiño

Colombia, pero, temo que se circunscriben, en muchos casos, a incluir la sistematización entre las opciones de grado y a introducir cursos sobre el tema en la malla curricular, en ocasiones, con carácter opcional. La sola lógica formal de incluir en los planes de estudio, le resta potencialidad a una relación que puede ser significativa para fortalecer la vida académica de los programas, en asuntos intra y extracurriculares, que involucran: los procesos de formación, el cumplimiento de la responsabilidad social que compete a las universidades que, para el caso, se realiza de manera preponderante a través de las prácticas académicas y el aporte al desarrollo del Trabajo Social.

Repensar el lugar que puede ocupar la sistematización en los currículos de nuestras escuelas implica retomar los cuestionamientos que solemos hacer a viejas dicotomías, que atribuimos a las lógicas tradicionales de la enseñanza, del quehacer profesional y de la investigación (teoría-práctica, intervención-investigación, sujeto-objeto de investigación, ejercicio profesional-política, acción-reflexión, profesional-sujeto popular, fines-medios, saberes populares-conocimiento científico, especificidad-pluralidad, práctica-producción de conocimiento y docente-discente, entre otras). Es necesario revisar la coherencia entre los discursos y las dinámicas curriculares en que se efectúa la formación profesional (respecto a: la historia y los desarrollos del Trabajo Social, la práctica académica, la investigación y los aportes interdisciplinares, la ciudadanía, entre otros).

La formación en sistematización es significativa para Trabajo Social, puede contribuir a que avancemos en la compleja tarea de re-conocer críticamente nuestras prácticas, apropiarlas, aprender de ellas y proyectar lo aprendido a otras experiencias y a espacios sociales, institucionales y académicos ocupados de lo social. Desde las lógicas de la Sistematización, es posible consolidar los virajes epistemológicos referidos a la investigación y a la acción, en coherencia con los fines de emancipación social. Se trata de perspectivas académicas que, aunque valoran el acervo de conocimientos desarrollados por las Ciencias Sociales, buscan superar el desdén con el que estas, tradicionalmente, han subvalorado otras formas de saber, "no científicas". Me refiero, de una parte, a los saberes que emergen y circulan en las interacciones de la vida cotidiana, en que se hilvanan las culturas y, de otra, a los que se construyen en los procesos sociales (prácticas, organizaciones, movimientos sociales). Se trata de saberes situados, histórica y territorialmente, en el marco de "una sociedad planetaria" signada por la desigualdad y las injusticias sociales de diverso orden (de género, de generación, ambientales, étnicas, de diversidad sexual, de clase social, entre muchas otras), en las que millones de personas luchan por su existencia. En esta dirección se sitúa la interpelación del profesor Martín-Barbero (2009)

¿Y cómo escapar de esas fronteras con las que la Academia arma el muro que intelectualmente la distancia del país si no es poniéndose a la escucha de lo que en este país suena, habla, grita, insulta, blasfema, al mismo tiempo que inaugura, inventa, oxigena, libera, emancipa, crea? Estamos exigidos de una nueva manera de pensar e investigar que, en medio de la frenética globalización que acosa a las culturas, nos exige "reconstruir los sentidos locales", aun los de las 
Cifuentes-Patiño

prácticas y las dimensiones más mundializadas de la vida social, pues toda interacción cultural es realizada siempre por actores situados, y los significados de las prácticas efectuadas o de los derechos reclamados siempre remitirán en últimas al uso, a los usos sociales temporal y espacialmente arraigados. Lo que desde esa perspectiva descubrimos es que los saberes sociales no están ahí sólo para ser acumulados y transmitidos sino para ser ejercidos ciudadanamente. ( $p$. 12)

En esta edición de la revista Prospectiva, autoras y autores dan a leer sus historias, sus reflexiones o los resultados de sus experiencias de sistematización. Estos textos solo se realizan en la lectura crítica de ellos y en las resonancias que tengan en las reflexiones, las conversaciones y las acciones de quienes los lean.

Este número de la revista es una invitación a seguir tejiendo el tema académicamente y a realizarlo en prácticas inspiradas en horizontes de emancipación social, de cara a los desiguales e injustos ordenamientos sociales de los países del continente, con la esperanza en que otros mundos, más propicios a la vida, a todas las formas de ella, sean posibles.

\section{Referencias bibliográficas}

Aylwin, N. (1999). Identidad e historia profesional. Revista Colombiana de Trabajo Social, (13), 7-23.

Cifuentes-Patiño, M. R. (2015). La sistematización en Trabajo Social: entre la práctica y la investigación. En Facultad de Humanidades y Ciencias Sociales Universidad Mariana, Reflexionando las disciplinas. Memorias del IV, V y VI Congreso Internacional Reflexionando las disciplinas (pp. 129-160). San Juan de Pasto, Colombia: Universidad Mariana.

Cifuentes-Patiño, M. R. (2019). Justicia, construcción de paz y Trabajo Social. Manuscrito inédito. Universidad de Caldas. Facultad de Ciencias Jurídicas y Sociales. Departamento de Desarrollo Humano.

Consejo Nacional para la Educación en Trabajo Social. (2020). Reflexiones para actualizar los lineamientos de los currículos de Trabajo Social, Colombia, 2020. Manuscrito en preparación. Consejo Nacional para la Educación en Trabajo Social.

De Sousa, B. (2005). La universidad en el siglo XXI: Para una reforma democrática y emancipadora de la universidad. México: UNAM.

Fraser, N. (2015). Fortunas del feminismo. Del capitalismo gestionado por el estado a la crisis neoliberal. Madrid y Quito: Traficantes de Sueños /IAEN.

Gadamer, H. (2004). Verdad y método II. (6 ed.). Salamanca: Ediciones Sígueme.

Gadamer, H. (2005). Verdad y método I. (11 ed.) Salamanca: Ediciones Sígueme.

Ghiso, A. (2011). Sistematización. Un pensar el hacer, que se resiste a perder su autonomía. Decisio, (28), 03-08.

Leal, G., y Malagón, E. (2006). Historia del Trabajo Social Latinoamericano. Estado del arte. Trabajo Social, (8), 45-61. 
Cifuentes-Patiño

Martín-Barbero, J (2009). Entre saberes desechables y saberes indispensables [Agendas de país desde la comunicación]. Bogotá, Colombia: FES.

Martínez, S. (agosto, 2020). Pensar la formación en Trabajo Social. Reflexiones urgentes. En Debates para la fundamentación curricular del programa de Trabajo Social en el siglo XXI. Universidad de Caldas, Manizales, Colombia.

Molano-Bravo, A. (2020). Cartas a Antonia. Bogotá, Colombia: Editorial Aguilar.

Molina, M. (2010). Trabajo Social: el viejo debate disciplina o profesión y las implicancias en la construcción de la autonomía profesional. En V Congreso Internacional y VIII Nacional de Trabajo Social, Universidad de Costa Rica, Alajuela, Costa Rica.

Mosquera-Rosero-Labbé, C. (2013). Pluralismos epistemológicos: hacia la valorización teórica de los saberes de la acción. Una reflexión desde la intervención social a la población afrocolombiana desplazada. En M. H. Ramírez (Comp.), La investigación y la práctica en trabajo social (pp. 53-84). Bogotá, Colombia: Universidad Nacional de Colombia.

Ricoeur, P. (2001). Tiempo y narración. Configuración del tiempo en el relato de ficción II. (3 ed.). México: Siglo veintiuno editores.

Touraine, A. (2000). ¿Podremos vivir juntos? Argentina: Fondo de Cultura Económica.

Viveros, M. (2016). La interseccionalidad: una aproximación situada a la dominación. Debate Feminista, 52, 1-17.

Young, I. (2000). La justicia y la política de la diferencia. Madrid. España: Ediciones Cátedra. 


\section{OTROS ARTÍCULOS DE PROSPECTIVA No. 31 DE 2021}

\section{PRESENTACIÓN}

Presentación. Reflexiones sobre desafios al publicar sistematizaciones

Rosa María Cifuentes-Gil

\section{EDITORIAL}

Reflexiones sobre Trabajo Social: aportes de la Sistematización

María Rocío Cifuentes-Patiño

\section{ARTÍCULOS}

Hacer lo que se sabe, pensar lo que se hace. La sistematización como modalidad investigativa Alfonso Torres-Carrillo

Aportes y desafios de la Sistematización de experiencias en el Trabajo Social y la extensión crítica. Apuntes y reflexiones desde la perspectiva de la Educación Popular

María Rosa Goldar

Valeria Chiavetta

La sistematización en Trabajo Social y la epistemología feminista del punto de vista. Diálogos sobre la producción de conocimiento sustentada en experiencias

Ruth Noemí Parola

María Florencia Linardelli

La Sistematización investigativa de las experiencias: del baile de los que sobran a la fiesta de los que faltan

María Belén Ortega-Senet

Sistematización y Trabajo Social en Chile. El largo y sinuoso camino

Patricia Lorena Castañeda-Meneses

Ana María Salamé-Coulon
Sentipensar la pandemia COVID-19 desde la sistematización de la experiencia en Trabajo Social: reflexiones del profesor Oscar Jara Holliday

Elia Sepúlveda-Hernández

La sistematización de experiencias, una investigación social cualitativa que potencia buenas prácticas de convivencia y gobierno. La experiencia de un conjunto residencial multifamiliar en Cali, Colombia Martha Lucia Echeverry-Velásquez Manuela Prada-Dávila

Construcción de subjetividades epistemológicaspolíticas de profesoras y profesores de Investigación social en una universidad privada y confesional en Bogotá

Giovanni Mora-Lemus

Sistematización de la experiencia Reconocimiento de los derechos humanos del adulto mayor en dos familias residentes en Cali y Valledupar (Colombia)

Lina María Cuello-Lacouture

Jimena del Pilar Jaramillo-Jaramillo

La memoria transformadora como estrategia de intervención profesional en los procesos de reconciliación social: comprensión a partir de mujeres campesinas, excombatientes y jóvenes en Manizales, Colombia

Yeimmy Stephania Corredor-Sotelo

Juliana Fuertes-Fuertes

Sistematización de una estrategia de educación informal implementada en personas privadas de la libertad en el establecimiento penitenciario de mediana seguridad y carcelario de Barranquilla, Colombia

Rafael Humberto Herrera-Mercado Rafael Alberto Zambrano-Vanegas 
Aportes significativos del proceso de intervención comunitaria con la Escuela Popular de Comunicación Alternativa Jaime Garzón de la ciudad de Cúcuta, Colombia

Carlos Lasso-Urbano

La sistematización de la intervención como metodología de investigación en Trabajo Social. Importancia práctica y teórica de la fase de recogida de datos en la intervención social según experiencia del Programa de Apoyo a las Familias en Zaragoza, España

Elisa Esteban-Carbonell

Nuria Del Olmo-Vicén

Papel de la sistematización de experiencias en los procesos de evaluación de intervenciones de salud pública en la Comuna Saludable por la Paz, Cali - Colombia

Jenny Faisury Peña-Varón

Paola Andrea Marín-Velásquez

Janeth Mosquera-Becerra

Experiencia de intervención social en hogares comunitarios integrales del barrio Alfonso Bonilla Aragón, Cali - Colombia

Julián Alexander Montaño-Cárdenas

Las políticas sociales y el gobierno de la "población indígena". Estrategias y regulaciones en el multiculturalismo chileno

Rodrigo Agustín Navarrete-Saavedra

Representaciones sociales sobre estilo de autoridad y tipos de interacción en cuidadores de residencias de protección infantil en Chile

Marcelo Gallegos-Fuentes
Carmen Gloria Jarpa-Arriagada

Reflexiones sobre inseguridad social y cuestiones penales. Una respuesta estratégica a partir de experiencias de cooperativismo con ex detenidos en Argentina

Analia Elizabeth Otero

Yael Yanina Barrera

Desarrollo y salud: la emergencia de un nuevo paradigma

Jesús María Sánchez-Ordóñez

Trabajo Social en ejercicio libre: la perspectiva profesional en España

Paula Frieiro-Padín

Tamara Fernández-Arias

Rubén González-Rodríguez

\section{RESEÑAS}

Social Work and the City: Urban Themes in 21stCentury Social Work

Felipe Saravia-Cortés

Respuestas del Trabajo Social ante emergencias sociales y problemáticas sociales complejas de México y España

Felipe Saravia-Cortés

El feminismo, el género y la profesionalización del trabajo social en Colombia (1936-2004)

Ambar Oriana Serna-Lombo

El puño invisible. Arte, revolución y un siglo de cambios culturales

Carlos Arturo Robledo-Marín

\section{PROSPECTIVA}

No. $31 \bullet$ ene.-jun. 2021

e-ISSN: 2389-993X • Universidad del Valle 